\title{
Ein guter Grund zum Feiern!
}

\author{
125 Jahre „ZWR“ - Das ist ein Grund zum Feiern, fanden ZWR- \\ Chefredakteurin Dr. Cornelia Gins und Volker Niem, zuständi- \\ ger Programmplaner im Georg Thieme Verlag. Und so luden \\ sie für den 30. Juni Vertreter aus Zahnmedizin und Dentalin- \\ dustrie ein, um mit ihnen gemeinsam auf die Erfolgsgeschichte \\ der traditionsreichen Fachzeitschrift anzustoßen.
}

1891 als „Zahnärztliche Rundschau“ gegründet, gehört die „ZWR - Das deutsche Zahnärzteblatt“ zu den weltweit ältesten Periodika für Zahnmediziner. Im Laufe der Jahre gingen verschiedene Titel wie
Jahren begleitet. 1956 hatte der Zahnarzt Dr. Helmut Gins die Chefredaktion des Titels übernommen. Als er 1983 aufgrund einer Erkrankung diese Aufgabe von einem Tag auf den anderen nicht mehr aus-

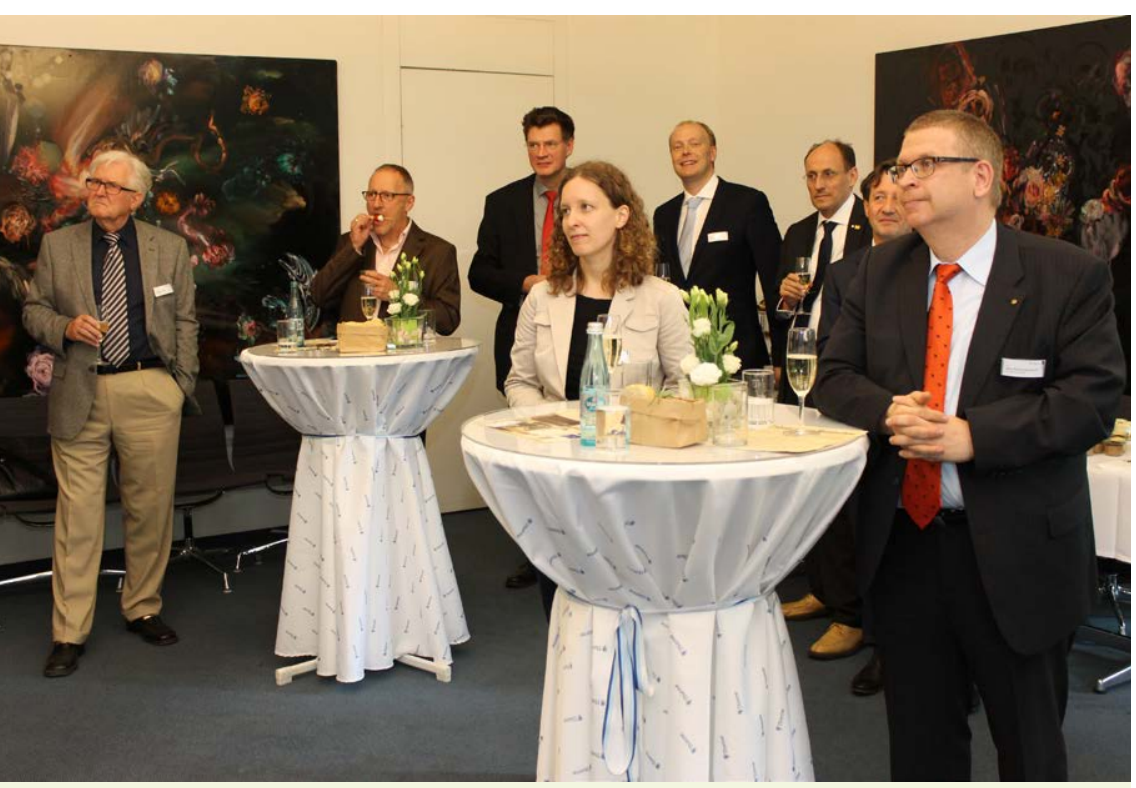

Nach dem Come together hatten die Gäste der Jubiläumsfeier Gelegenheit, die im Haupthaus des Georg Thieme Verlags allgegenwärtige Kunstsammlung der Familie Hauff näher zu betrachten.

üben konnte, übernahm kurzerhand seine Tochter Cornelia, damals frischgebackene Zahnärztin, die kommissarische Leitung. „Diese Übergangslösung währt nun schon über 30 Jahre“, schmunzelt Gins in ihrer Festrede. 1991 übernahm sie schließlich die hauptamtliche Verantwortung als Chefre-

„Zahnärztliche Welt“, „Zahnärztliche Reform“ oder „Zahnarzt Journal“ in der Zeitschrift auf. Ab 1968 gab der in Heidelberg ansässige Hüthig Verlag den Titel heraus. Seit 1999 entwickelt der Georg Thieme Verlag die ZWR gemeinsam mit Chefredakteurin Dr. Cornelia Gins weiter.

Bei Prosecco und kleinen Leckereien ließen die Gäste die Geschichte der Fachzeitschrift Revue passieren. Dabei würdigte der Verlag insbesondere die Leistung der Familie Gins, die die ZWR seit nunmehr 60

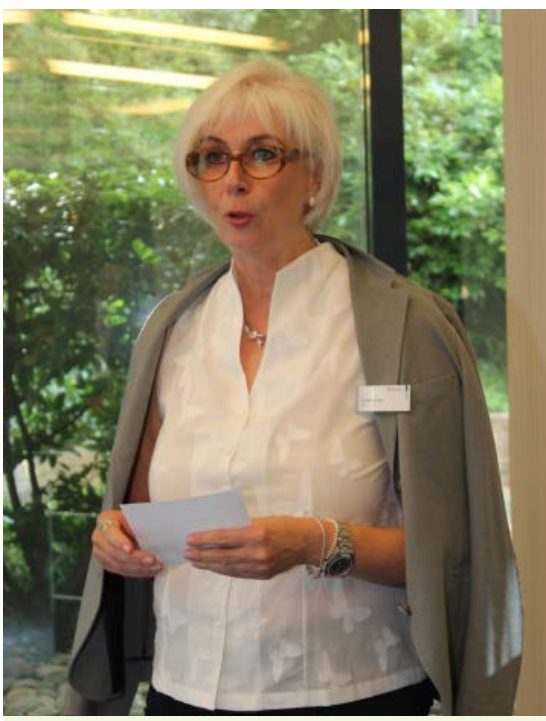

Dr. Cornelia Gins gab den Gästen einen kleinen Einblick in die Geschichte der ZWR.

gab Gins die ihr entgegengebrachte Wertschätzung weiter. Engagement und Leidenschaft aller Beteiligten, ein gutes Konzept und das richtige Know-how - ohne das geht es nicht. Da waren sich alle Akteure und Gäste einig.

Nach einem Come together im Hauptsitz des Georg Thieme Verlags in Stuttgart hatten die Gäste die Gelegenheit, die Kunstsammlung der Verlegerfamilie Hauff kennenzulernen. Bei einem gemeinsamen Abendessen im Restaurant Steigenberger Graf Zeppelin ließ die Jubiläumsgesellschaft den Tag gemeinsam ausklingen.

src

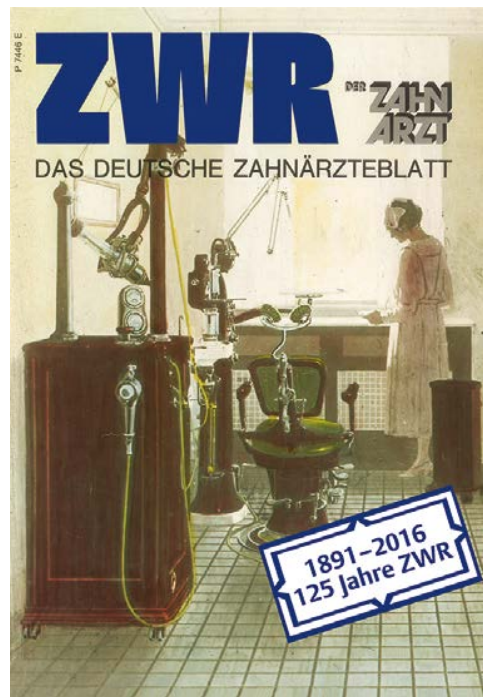

